\title{
Below- and aboveground architecture of Androstachys johnsonii prain: topological analysis of the root and shoot systems
}

\author{
Tarquinio Mateus Magalhães・Thomas Seifert
}

Received: 18 September 2014 / Accepted: 19 May 2015 / Published online: 30 May 2015

(C) The Author(s) 2015. This article is published with open access at Springerlink.com

\begin{abstract}
Aim This study aimed to analyse the topological branching pattern, area-preserving branching, and fractal branching pattern (self-similarity) of the root and shoot systems of 93 Androstachys johnsonii trees with diameter-at-breast heights of 5-32 cm.

Methods Topological parameters were calculated.

Results Visual analysis indicated herringbone-like branching pattern for both the root and shoot systems. However, the topological index (TI) and topological trend (TT) suggested otherwise. This discrepancy was attributed to the fact that $A$. johnsonii has multiple laterals per stem/taproot node, suggesting that the topological indexes (TI and TT) might yield biased conclusions regarding the branching pattern when the main axis has multiple laterals per node. Hence, modified topological index (TIM) that could be applied in the cases of multiple laterals per node while conserving the values of TI for cases with one lateral per node
\end{abstract}

Responsible Editor: Alain Pierret.

T. M. Magalhães

Departamento de Engenharia Florestal, Universidade Eduardo

Mondlane, Campus Universitário Principal, Edifício n. 1,

Maputo, Mozambique

T. M. Magalhães $(\bowtie) \cdot T$. Seifert

Department of Forest and Wood Science,

University of Stellenbosch, Private Bag X1 Matieland 7602,

Stellenbosch, South Africa

e-mail: tarqmag@yahoo.com.br

T. Seifert

e-mail: seifert@sun.ac.za was developed; the modified index was more efficient and realistic than TI.

Conclusion The area preserving branching was confirmed for each stem node confirming thus, the selfsimilar branching. For the root system, the areapreserving branching was only confirmed for the first node; therefore, self-similarity was not confirmed.

Keywords Topology · Leonardo da Vinci rule . Branching pattern $\cdot$ Self-similarity $\cdot$ Mecrusse

\section{Introduction}

Architecture of biological objects refers to the spatial configuration of the assemblage of subunits such that the overall configuration has some functional significance (Lynch 1995). Root architecture refers to the spatial configuration of the root system (Lynch 1995) and, analogously, shoot architecture refers to the spatial configuration of the shoot system.

Root architecture determines the ability of plants to exploit soil resources (Lynch 1995), thereby affecting water and nutrient acquisition, carbon metabolism, and environmental stress resistance (Trubat 2012). Shoot architecture, on the other hand, affects the allocation of light to leaf area and the manner in which leaves are arranged and displayed (Valladares 1999), thereby playing an important role in plant growth and survival (Valladares and Pearcy 2000).

Plants are known to respond to nutrient limitation by modifying branching and root system architecture (Trubat 
et al. 2012; Lynch and Ho 2005) towards herringbone-like root system (Fitter 1987; Fitter et al. 1991). In a similar way the response to water limitation is also by inhibiting lateral branching (Malamy 2005) and thus promoting herringbone-like root systems (Fitter 1987). Therefore, during the life of a tree, from seedling to adult stage, the root system can undergo transformations according to the availability of nutrients and water resources.

The majority of the existing studies on root system architecture focus on seedlings (Martínez-Sánchez et al. 2003; Trubat et al. 2012; Chiatante et al. 2004; Berntson 1997; Fitter and Stickland 1991; Larkin et al. 1995; Nicotra et al. 2002; Tworkoski and Scorza 2001; Cortina et al. 2008; Riccardo 2007) and saplings (Coll et al. 2008; Spanos et al. 2008; Salas et al. 2004; van Noordwijk and Purnomosidhi 1995; Oppelt et al. 2001); this is probably because of the difficulty in excavating the root system of adult trees. Further, if the architecture of the root system of an adult tree is studied, often the root system is not totally removed and is therefore only partially analysed (Kalliokoski 2011; Kalliokoski et al. 2008; Soethe et al. 2007).

Field studies of below- and aboveground architecture are relatively scarce in Africa (Oppelt et al. 2000, 2001). To our knowledge, similar studies in Mozambique and, especially, on Androstachys johnsonii, an commercially important woodland tree species restricted only to Mozambique (Cardoso 1963), are lacking. Hence, we aimed to investigate branching behaviour and determine the application of the Leonardo da Vinci rule and fractal branching pattern (self-similarity) of the root and shoot systems of $A$. johnsonii.

\section{Material and methods}

\section{Study area}

Mecrusse is a forest type where the main species, and occasionally, the only one in the upper canopy, is A. johnsonii. It is the dominant and co-dominant species with a relative cover varying from 80 to $100 \%$ (Matilla and Timane 2005).

In Mozambique $\left(18^{\circ} 15^{\prime} \mathrm{S}\right.$ and $\left.35^{\circ} 00^{\prime} \mathrm{E}\right)$, Mecrussedominated woodlands are mainly found in Inhambane and Gaza Provinces and in Massangena, Chicualacuala, Mabalane, Chigubo, Guijá, Mabote, Funhalouro, Panda, Mandlakaze, and Chibuto Districts. The east-most Mecrusse forest patches, covering the last five districts, were defined as the study area. The study area has an extension of 4,502,828 ha (DINAGECA 1997), of which 226,013 ha $(5 \%)$ are covered by Mecrusse woodlands.

In the study area, the climate is dry tropical except in the west part of Panda district and south-west part of Mandlakaze district where the climate is humid tropical (Dinageca 1997; Mae 2005a; b, c, d, e). The climate is divided into two seasons: warm or rainy season from October to March and cool or dry season from March to September (Mae 2005a; b, c, d, e).

The mean annual temperature is generally greater than $24{ }^{\circ} \mathrm{C}$, and the mean annual precipitation varies from 400 to $950 \mathrm{~mm}$ (Dinageca 1997; Mae 2005a; b, c, d, e). According to the FAO classification (FAO 2003), the soils in the study area are mainly Ferralic Arenosols covering more than $70 \%$ of the study area (Dinageca 1997). Arenosols, Umbric Fluvisols, and Stagnic soils are also predominant in the north-most part of the study area (Dinageca 1997).

The study area is characterised by shortage of water resources as well as precipitation; of the five districts comprising the study area, only Chibuto and Mandlakaze districts have water resources (Dinageca 1997; Mae 2005a; b, c, d, e).

\section{Data collection}

Ninety-three trees with diameter-at-breast heights varying from 5 to $32 \mathrm{~cm}$ and heights varying from 5.69 to $16 \mathrm{~m}$ were randomly selected within 23 circular plots of $20-\mathrm{m}$ radius and divided into root and shoot systems. The entire root system was completely excavated, and the distal diameters before branching and the proximal diameters after branching were measured at each node by using a calliper or calliper rule. Similarly, the shoot system was measured. Only the primary laterals (lateral roots or branches), those originating from the main axis (taproot or stem), were considered. The link length (internode distance: internal link; distance from the last node to the apex (meristem): external link; Fig. 1) was measured using a tape.

Additionally, the dry weight of the taproot, primary lateral roots, higher-order lateral roots (mainly secondary roots), primary branches, and higher-order branches were determined by multiplying the ratio of fresh- to oven-dry weight of samples taken from those components by the total fresh weight of the relevant component. Dry weight of the stem was obtained by 


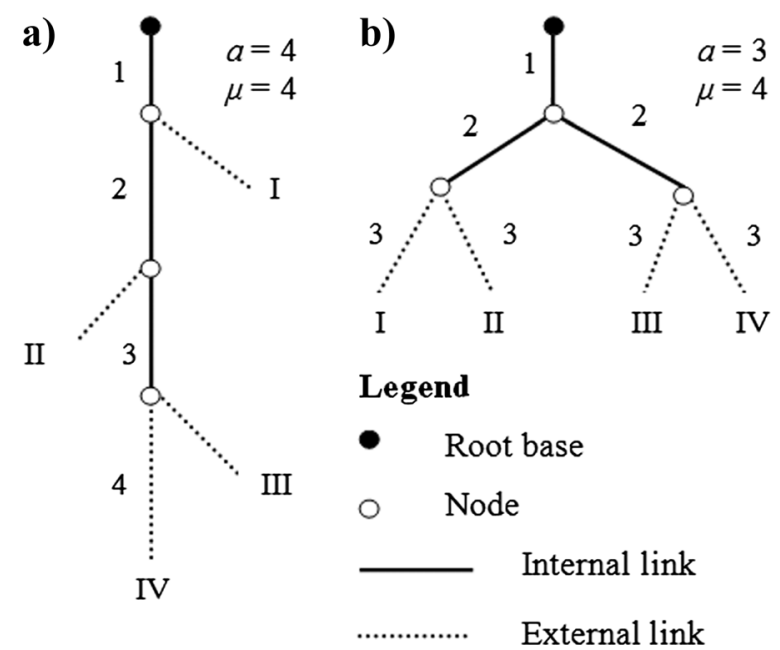

Fig. 1 Altitude and magnitude for (a) herringbone and (b) dichotomous root systems. The altitude is numbered in Arabic numerals and the magnitude is numbered in Roman numerals

multiplying the estimated density of each sample by the stem volume. Dry weights of the root and shoot systems were obtained by summing the dry weights of their constituent components. This information was used to determine how much biomass is allocated in heigherorder axes (branches and roots).

Data processing and analysis

The altitude $(a)$ and magnitude $(\mu)$ of topological parameters were determined for each root and shoot system. Altitude refers to the number of links in the longest individual path in the system (Fitter 1987; Fitter and Stickland 1991; Echeverria 2008), from the root or shoot base to an external link (Coll et al. 2008; Echeverria 2008), and magnitude refers to the total number of external links (those ending with a meristem; Fitter et al. 1991; Fitter and Stickland 1991; Riccardo 2007; Coll et al. 2008) (Fig. 1).

The branching tendency of the root and shoot systems to one of the two extremes of branching patterns, herringbone and dichotomous, was estimated by calculating two distinct indexes, the topological index (TI) and the topological trend (TT). TI was computed as the slope of the linear regression between $\log _{10}(a)$ and $\log _{10}$ $(\mu)$ as proposed by Fitter et al. (1991); it can also be computed as follows: $\log _{10}(a): \log _{10}(\mu)$ ratio (Riccardo 2007; Glimskar 2000), in the cases of single root or shoot systems. TI values close to 1 are associated with herringbone branching pattern and those close to 0.53 are associated with random growth of the roots or branches (Fitter et al. 1991). TT was computed using Equation 1 (Trencia 1995). TT values close to 1 are associated with herringbone branching pattern, and those close to 0 are associated with dichotomous branching pattern (Trencia 1995). Therefore, TI values were tested under the null hypothesis of being equal to 1 and 0.53 , and average TT values were tested under the null hypothesis of being equal to 1 and 0 by using Student's $t$-test.

$\mathrm{TT}=\left[\mathrm{Pe} 0-\mathrm{Pe}_{(\min )}\right] /\left[\mathrm{Pe}_{(\max )}-\mathrm{Pe}_{(\min )}\right]$

where $\mathrm{Pe} 0$ is the number of observed $\mathrm{Pe}$, and $\mathrm{Pe}$ (external path length) is the sum of the number of links in all paths from all external links to the base link (Fitter 1987). $\mathrm{Pe}_{(\max )}$ and $\mathrm{Pe}_{(\min )}$ are the possible maximum and minimum $P e$ values, respectively, and are computed as $\mathrm{Pe}_{(\max )}=1 / 2\left(\mu^{2}+3 \mu-2\right)$ and $\mathrm{Pe}_{(\min )}=\mu\left(\mathrm{a}_{\min }+1\right)-2 \mathrm{a}_{\min }-1$, where $\mathrm{a}_{\min }=\log _{2}$ $(\mu-1)+2$.

The proportionality factor $(p)$, a parameter that describes the changes in cross-sectional area (CSA) from parent root or branch to the total daughter roots or branches (van Noordwijk and Mulia 2002), i.e., the changes of CSA during branching (Soethe et al. 2007) was computed using Equation 2. The allocation factor $(q)$, a parameter that describes the equity in CSA among daughter roots or branches (van Noordwijk and Mulia 2002) was computed using Equation 3. Since only the primary roots or branches were considered, the parent root or branch was always the taproot or stem and the daughter roots or branches included the taproot or the stem after branching and the daughter roots or branches after branching.

$p=\frac{D^{2} \text { before branching }}{\sum D^{2} \text { after branching }}$

$q=\frac{\max D^{2} \text { after branching }}{\sum D^{2} \text { after branching }}$

where $\mathrm{D}$ is the root or branch diameter.

The Leonardo da Vinci rule or the area-preserving branching was tested for the root and shoot systems by using four different methods. First, the average parameters $p$ and $q$ calculated for each ith node of the 93 trees and for the entire population of nodes were tested under the null hypothesis of being equal to 1 and 0.5 , respectively, by using Student's $t$-test. Second, these 
parameters ( $p$ and $q$ ) were tested for independence to the link diameter by running a linear regression of $p$ and $q$ against the link diameter and testing the significance of the regression slope. Third, the diameter exponent $\Delta$ from Equation 4 of each stem or taproot node in each tree was estimated separately by nonlinear optimisation using Newton coordinate search, and the average was obtained per ith node and per total number of nodes. The diameter exponent is the value of exponent $\Delta$ that is used to solve Equation 4.

$d_{b}^{\Delta}=\sum_{a=1}^{n} d_{a}^{\Delta}$

where $d_{b}$ is the distal diameter before branching, and $d_{a}$ is the proximal diameter after branching. Finally, assuming $\Delta=2$, the regression through the origin (RTO) of the CSA before branching against total CSA after branching was run by using Equation 5 reported by Spek and van Noordwijk (1994).

$d_{b}^{2}=\alpha \sum_{a=1}^{n} d_{a}^{2}$

The average parameter $\Delta$ and the regression slope $\alpha$ were tested under the null hypothesis of being equal to 2 and 1 , respectively, by using Student's $t$-test. The regression slope $\alpha$ is also referred to as the proportionality factor $(p)$ by some authors such as Oppelt et al. (2001), although their values estimated from equations 2 and 5 are distinct. In this study, these parameters were treated distinctly.

In the cases where the average parameter $p$ and slope $\alpha$ were statistically different from 1 and the average parameter $\Delta$ was not statistically different from 2 , the area-preserving branching was confirmed. This was because if $p=1$ (i.e., $\Delta=2$ or $\alpha=1$ ), the CSA does not change across a branching point (node), whereas if $p>1$ (i.e., $\Delta>2$ or $\alpha>1$ ), the CSA decreases from the parent to daughter and, if $p<1$ (i.e., $\Delta<2$ or $\alpha<1$ ), it increases (Kalliokoski 2011; Oppelt et al. 2001; Richardson and zu Dohna 2003). Further, in the cases where the average parameter $q$ was not found to be statistically different from 0.5, equity in CSA was implied among daughter roots or branches.

Furthermore, in the cases in which the areapreserving branching was observed for all nodes across the stem or taproot, the self-similar branching pattern was confirmed (van Noordwijk and Mulia 2002; Soethe et al. 2007 and Richardson and zu Dohna 2003). In other words, if the branching parameters ( $p$ and $q$ ) for all nodes across the stem or taproot were not found to be dependent on the link diameter, the self-similar branching pattern was confirmed (Salas et al. 2004; van Noordwijk and Purnomosidhi 1995). All the statistical analyses were performed at the $5 \%$ significance level using Microsoft Excel Data Analysis Tools.

\section{Results}

Topology

The branching topology of the root and shoot systems of A. johnsonii can be considered as perfectly to nearly herringbone, respectively, i.e., the stem or taproot is the main axis (Kalliokoski 2011) and the longest and thickest branch (Richardson and zu Dohna 2003; Fig. 2) as opposed to dichotomous branching topology where the parent branch divides into two daughter branches of the same size (Richardson and zu Dohna 2003), i.e., branching occurs with equal probability on all links (Kalliokoski 2011). However, while the shoot system occasionally violated the definition of herringbone branching by having branching laterals, the root system conformed to the definition by Riccardo (2007) and Kalliokoski (2011) since it mostly had nonbranching laterals.

The shoot system consisted mostly of 7 nodes with an average of 2 laterals per node, a minimum of 1 and maximum of 4 . The root system, on the other hand, consisted mostly of 4 nodes with $75 \%$ of the laterals
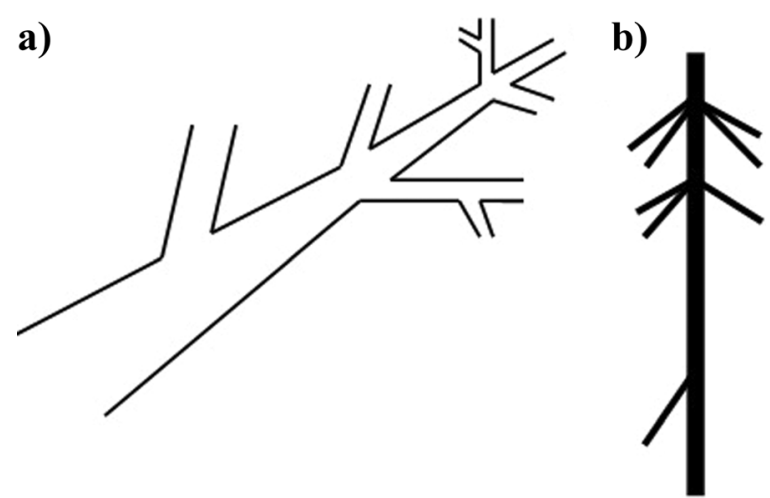

Fig. 2 Topological representation of the (a) shoot system and (b) root system. All the laterals of the root system emerge from the main axis (taproot); however, in the shoot system, branching of some primary laterals is noted 
located in the first and second nodes. The average number of laterals per node in the root system was 4 and 3 for the first and second nodes, respectively, and 2 per remaining nodes; the minimum and maximum numbers of laterals per node were 1 and 11 , respectively. Table 1 provides details on the number of nodes and laterals per node for the root and shoot systems.

In all, $81 \%$ of the stem nodes had only 1 lateral; $15 \%$, had 2 and 3 ; and $1 \%$, had 3 and 4 laterals. Further, $32 \%$ of the taproot nodes had only 1 lateral, and 17,13 , and $6 \%$ had 2,3 , and 4 laterals, respectively; in $32 \%$ of the nodes, the number of laterals varied from 5 to 11 . In the shoot system, the laterals per node increased with height; on the other hand, in the root system, the laterals decreased with depth. The diameters of the laterals at the insertion point decreased with height (aboveground) and depth (belowground).

In the shoot system, the average link length per tree varied from 115 to $719 \mathrm{~cm}$, with an overall weighted average of $193 \mathrm{~cm}$; on the other hand, in the root system, it varied from 35 to $235 \mathrm{~cm}$, with an overall weighted average of $90 \mathrm{~cm}$. The average link diameter in the shoot system was $9.73 \mathrm{~cm}$, varying from a minimum of 2.5 to a maximum of $32 \mathrm{~cm}$; in the root system, the average link diameter was $12.59 \mathrm{~cm}$, ranging from 3.5 to $47 \mathrm{~cm}$. The biomass allocated in each tree component is given in the Table 2; where it can be seen that higher-order roots account, on average, with $2.922 \%(0.704 \mathrm{~kg})$ of the biomass of all lateral roots $(24.083 \mathrm{~kg})$; and higherorder branches account with $5.631 \%(3.130 \mathrm{~kg})$ of the biomass of all branches $(55.586 \mathrm{~kg})$.

The lower amount of biomass allocated to higherorder axes (roots and branches) support the visual analysis results that the branching topology of the root and shoot systems is herringbone; with the root system showing a tendency to a perfect herringbone branching, judging by the amout of biomass allocated to higher-order roots when compared to the shoot system.

The altitude of the shoot system varied from 2 to 8 , with an average of 4.6, and the magnitude varied from 2 to 13 , with an average of 5.40. The TI for the shoot system was 0.70 , consequentelly the hypotheses of being equal to $1(P<0.0001)$ or $0.53(P<0.0001)$ were rejected. The altitude of the root system varied from 3 to 5 , with an average of 2.82, and the magnitude varied from 2 to 15 , with an average of 7.29. The TI for the root system was 0.30 , and the hypotheses of being equal to $1(P<0.0001)$ or 0.53 $(P=0.0002)$ were rejected.

The external path length $(\mathrm{Pe})$ of the shoot system varied from 4 to 68 , with an average of 21.40; the average TT value was 0.90 ; however, the hypotheses of being equal to $1(P<0.0001)$ or $0(P<0.0001)$ were rejected. Pe for the root system varied from 4 to 46 , with an average of 17.80 ; the average TT was 0.37 , and the hypotheses of being equal to $1(P<0.0001)$ or 0 $(P<0.0001)$ were rejected.

Table 1 Summary description of the number of nodes and laterals in the sampled trees

\begin{tabular}{|c|c|c|c|c|c|c|c|c|c|}
\hline & & $\begin{array}{l}\text { First } \\
\text { node }\end{array}$ & $\begin{array}{l}\text { Second } \\
\text { node }\end{array}$ & $\begin{array}{l}\text { Third } \\
\text { node }\end{array}$ & $\begin{array}{l}\text { Fourth } \\
\text { node }\end{array}$ & $\begin{array}{l}\text { Fifith } \\
\text { node }\end{array}$ & $\begin{array}{l}\text { Sixth } \\
\text { node }\end{array}$ & $\begin{array}{l}\text { Seventh } \\
\text { node }\end{array}$ & Total \\
\hline \multirow[t]{5}{*}{ Shoot system } & Number of nodes in the sampled trees & 86.00 & 80.00 & 69.00 & 44.00 & 23.00 & 6.00 & 1.00 & 309.00 \\
\hline & Number of branches after bifurcation & 175.00 & 168.00 & 158.00 & 110.00 & 57.00 & 20.00 & 3.00 & 691.00 \\
\hline & Average number of branches per node per tree & 2.03 & 2.10 & 2.29 & 2.50 & 2.48 & 3.33 & 3.00 & 17.74 \\
\hline & $\begin{array}{l}\text { Number of lateral branches after bifurcation } \\
\text { (excluding the stem) }\end{array}$ & 172.00 & 160.00 & 141.00 & 93.00 & 48.00 & 17.00 & 2.00 & 633.00 \\
\hline & $\begin{array}{l}\text { Average number of lateral branches per node } \\
\text { per tree (excluding the stem) }\end{array}$ & 2.00 & 2.00 & 2.04 & 2.11 & 2.09 & 2.83 & 2.00 & 15.08 \\
\hline \multirow[t]{5}{*}{ Root system } & Number of nodes in the sampled trees & 73.00 & 40.00 & 19.00 & 1.00 & & & & 133.00 \\
\hline & Number of lateral roots after bifurcation & 386.00 & 160.00 & 43.00 & 3.00 & & & & 592.00 \\
\hline & $\begin{array}{l}\text { Average number of lateral roots after } \\
\text { bifurcation per node per tree }\end{array}$ & 5.29 & 4.00 & 2.26 & 3.00 & & & & 14.55 \\
\hline & $\begin{array}{l}\text { Number of lateral roots after bifurcation } \\
\text { (excluding the taproot) }\end{array}$ & 327.00 & 134.00 & 39.00 & 2.00 & & & & 502.00 \\
\hline & $\begin{array}{l}\text { Average number of lateral roots after bifurcation } \\
\text { per node per tree (excluding the taproot) }\end{array}$ & 4.48 & 3.35 & 2.05 & 2.00 & & & & 11.88 \\
\hline
\end{tabular}


Table 2 Summary basic statistics of the biomass per tree $(\mathrm{kg})$ allocated in different tree components
$\mathrm{SD}$ is the standard deviation and $\mathrm{CV}$ is the coefficient of variation. The major components and their values are indicated in bold font

\begin{tabular}{lllllrr}
\hline$\#$ & Tree component & $\begin{array}{l}\text { Minimum } \\
(\mathrm{kg})\end{array}$ & \multicolumn{1}{l}{$\begin{array}{l}\text { Mean } \\
(\mathrm{kg})\end{array}$} & $\begin{array}{l}\text { Maximum } \\
(\mathrm{kg})\end{array}$ & SD (kg) & CV (\%) \\
\hline 1 & Taproot & 1.474 & 23.651 & 71.926 & 18.926 & 80.019 \\
2 & Primary lateral roots & 0.000 & 23.379 & 95.737 & 22.551 & 112.085 \\
3 & Higher-order lateral roots & 0.000 & 0.704 & 5.600 & 2.267 & 57.200 \\
4 & Lateral roots (2+3) & $\mathbf{0 . 7 4 6}$ & $\mathbf{2 4 . 0 8 3}$ & $\mathbf{1 0 0 . 8 1 5}$ & $\mathbf{2 3 . 9 4 5}$ & $\mathbf{9 9 . 4 2 8}$ \\
5 & Root system (1+4) & $\mathbf{2 . 5 4 5}$ & $\mathbf{4 7 . 7 3 5}$ & $\mathbf{1 6 2 . 1 0 5}$ & $\mathbf{4 1 . 2 1 0}$ & $\mathbf{8 6 . 3 3 1}$ \\
6 & Stem & 5.636 & 138.267 & 413.153 & 110.577 & 79.974 \\
7 & Primary branches & 2.310 & 52.456 & 209.586 & 57.492 & 109.600 \\
8 & Higher-order branches & 0.000 & 3.130 & 12.858 & 1.954 & 62.437 \\
9 & Branches $(\mathbf{7 + 8 )}$ & $\mathbf{2 . 5 8 3}$ & $\mathbf{5 5 . 5 8 6}$ & $\mathbf{2 1 1 . 3 2 0}$ & $\mathbf{5 7 . 3 5 5}$ & $\mathbf{1 0 3 . 1 8 3}$ \\
10 & Shoot system (6+9) & $\mathbf{9 . 8 2 3}$ & $\mathbf{1 9 6 . 6 5 9}$ & $\mathbf{5 9 0 . 8 6 3}$ & $\mathbf{1 6 3 . 7 1 3}$ & $\mathbf{8 3 . 2 4 7}$ \\
\hline
\end{tabular}

Branching parameters ( $p$ and $q)$

The average $p$ values per node for the shoot system varied from 0.99 to 1.05 , with an overall average of 1.03 (Table 3); none of the values were statistically different from $1(P \geq 0.05)$. For the root system, the average $p$ values per node varied from 1.02 to 2.65 , with an overall average of 1.41, and only the average $p$ value of the first node was not found to be statistically different from $1(P=0.7185)$. Therefore, the $p$ values suggested that the area-preserving branching was confirmed for all stem nodes, thereby ensuring the self-similar branching pattern. For the root system, the areapreserving branching was only confirmed for the first node; for the second and third nodes, the CSA was found to decrease with branching, since the average $p$ values were larger than 1.

The average $q$ values per node for the shoot system ranged from 0.46 to 0.60 , with an overall average of 0.56 ; however, these values were not statistically different from 0.5 only for the last three nodes (Table 4). For the root system, where the average $q$ values per node ranged from 0.45 to 0.53 with an overall average of 0.46 , only the second and third nodes had average $q$ values not different from 0.5 .

Since the diameters of the stems and taproots after branching were mostly larger than those of the laterals, the average $q$ values were not statistically different from 0.5 , suggesting that there is equity in terms of CSA between the stem or taproot after branching and the laterals. The average $q$ values markedly larger than 0.5 for the first, second, and third and for all stem nodes suggested that the largest share of the CSA was for the stem after branching. Similarly, average $q$ values markedly smaller than 0.5 for the first and all taproot nodes suggested that the largest share of CSA was in the laterals.

The linear regressions of $p$ against the link diameter for each stem node and for all stem nodes together were not significant (Adjusted $\mathrm{R}^{2}<0.015$ and $P>0.05$ ), suggesting

Table 3 Summary of the basic statistics for the branching parameter $p$

\begin{tabular}{|c|c|c|c|c|c|c|c|c|c|c|c|}
\hline \multicolumn{8}{|c|}{ Shoot system } & \multicolumn{4}{|c|}{ Root system } \\
\hline & $\mathrm{p} 1$ & $\mathrm{p} 2$ & p3 & $\mathrm{p} 4$ & p5 & p6 & $\mathrm{p}$ for all nodes & $\mathrm{p} 1$ & $\mathrm{p} 2$ & p3 & $\mathrm{p}$ for all nodes \\
\hline Minimum & 0.5025 & 0.692 & 0.2549 & 0.4612 & 0.5104 & 0.5900 & 0.2549 & 0.4073 & 1.0544 & 0.7987 & 0.3352 \\
\hline Mean & 0.9968 & 1.0541 & 1.0518 & 1.0245 & 1.0334 & 0.9925 & 1.0306 & 1.0169 & 2.6541 & 1.3887 & 1.4182 \\
\hline Maximum & 1.5444 & 2.2669 & 1.7622 & 2.3607 & 2.3059 & 2.1202 & 2.3607 & 2.8412 & 7.4903 & 2.2368 & 7.4903 \\
\hline $\mathrm{SD}$ & 0.1749 & 0.2481 & 0.3021 & 0.4621 & 0.3666 & 0.5786 & 0.3100 & 0.3994 & 1.6807 & 0.3448 & 1.2750 \\
\hline $\mathrm{CV} \%$ & 17.5461 & 23.5386 & 28.7237 & 37.1072 & 35.4722 & 58.2980 & 29.1482 & 39.2799 & 63.3242 & 24.8304 & 89.9028 \\
\hline Probability & 0.8659 & 0.0546 & 0.1587 & 0.1035 & 0.6668 & 0.9759 & 0.0584 & 0.7185 & 0.0000 & 0.0001 & 0.0003 \\
\hline
\end{tabular}

$p i$ is the $p$ statistic for the $i$ th node 
Table 4 Summary of the basic statistics for the branching parameter $q$

\begin{tabular}{|c|c|c|c|c|c|c|c|c|c|c|c|}
\hline \multicolumn{8}{|c|}{ Shoot system } & \multicolumn{4}{|c|}{ Root system } \\
\hline & $\mathrm{p} 1$ & $\mathrm{p} 2$ & p3 & $\mathrm{p} 4$ & p5 & p6 & $\mathrm{p}$ for all nodes & p1 & $\mathrm{p} 2$ & p3 & $\mathrm{p}$ for all nodes \\
\hline Minimum & 0.3846 & 0.4773 & 0.2941 & 0.2667 & 0.2759 & 0.2375 & 0.2375 & 0.1714 & 0.2000 & 0.4091 & 0.1714 \\
\hline Mean & 0.6096 & 0.5902 & 0.5473 & 0.5062 & 0.5058 & 0.4554 & 0.5645 & 0.4483 & 0.4518 & 0.5334 & 0.4607 \\
\hline Maximum & 0.8367 & 0.8158 & 0.7647 & 0.8387 & 0.7083 & 0.6000 & 0.8387 & 0.8478 & 0.6970 & 0.6316 & 0.8478 \\
\hline SD & 0.0926 & 0.0781 & 0.1097 & 0.1297 & 0.1131 & 0.1455 & 0.1099 & 0.1870 & 0.1508 & 0.0735 & 0.1659 \\
\hline $\mathrm{CV} \%$ & 15.1835 & 13.2265 & 20.0488 & 25.6324 & 22.3619 & 31.9532 & 19.4659 & 41.7199 & 33.3873 & 13.7893 & 36.0118 \\
\hline Probability & 0.0000 & 0.0000 & 0.0006 & 0.7538 & 0.8077 & 0.4867 & 0.0000 & 0.0208 & 0.0500 & 0.0634 & 0.0000 \\
\hline
\end{tabular}

$q i$ is the $q$ statistic for the $i t h$ node

the independence of $p$ values from link diameter (Table 5, Fig. 3). The independence of $q$ values from link diameter for each stem node and for all stem nodes together was also confirmed (Adjusted $\mathrm{R}^{2}<0.018$ and $P>0.05$ ) except for the fourth node (Adjusted $\mathrm{R}^{2}=0.27$ and $P=0.0002$ ). The independence of branching parameters $(p$ and $q$ ) for all nodes to link diameter reconfirms the self-similar branching pattern of the shoot system (Salas et al. 2004; van Noordwijk and Purnomosidhi 1995).

For the root system, independence of $p$ values to link diameters was verified only for the first and third nodes (Adjusted $\mathrm{R}^{2}<0.039$ and $P>0.05$ ), and independence of $q$ values to link diameters was only confirmed for the first and second nodes (Adjusted $\mathrm{R}^{2}=0.028$ and $P>0.1$ ). The dependence of $p$ and $q$ to link diameter for all nodes suggested that there is no self-similar branching pattern for the root system. For the second taproot node, $p$ values increased with the link diameter (Fig. 3c).

\section{Diameter exponent $(\Delta)$}

For 25 of the 309 stem nodes and 34 of the 133 taproot nodes, there was no solution for $\Delta$, i.e., the nonlinear optimisation of Equation 4 did not converge. The nonconvergence was mainly because the diameters of these stem or taproot nodes after branching were larger than were those before branching.

For the shoot system, the average $\Delta$ per node ranged between 1.79 and 2.06, with an overall average of 1.99 (Table 6). The null hypothesis of average $\Delta$ to be equal to 2 was not rejected for any node or population of nodes $(P>0.09)$. This confirms the area-preserving branching for each stem node and the self-similar branching pattern.

For the root system, the average $\Delta$ per node ranged between 1.22 and 1.86 , with an overall average of 1.54
(Table 6). The null hypothesis of average $\Delta$ to be equal to 2 was not rejected only for the first node $(P=0.06)$. Therefore, the area-preserving branching was only reconfirmed for the first taproot node. The average $\Delta$ values for the second, third, and all nodes were markedly smaller than 2 , suggesting that the CSA increased with branching; contradicting the conclusion obtained by the proportionality factor $(p)$.

RTO of CSA before branching against CSA after branching

The slope $\alpha$ of RTO of CSA before branching against CSA after branching (Table 7) was not statistically different from $1(P>0.07)$ for any stem node or for the entire population of nodes. This result was expected since the average branching parameter $p$ was not significantly different from 1. These results also suggest the areapreserving branching for each stem node and for the entire population of nodes and thus the self-similarity.

For the root system, the slope $\alpha$ was not found significantly different from $1(P>0.05)$ only for the first node (as expected) and for the entire population of nodes. Therefore, the area-preserving branching was not observed for any subsequent branching points (nodes), and thus, self-similarity was not confirmed for the root system.

\section{Discussion}

Topology

The TI values of the shoot and root systems were statistically different from 1 and 0.53 , respectively, implying 


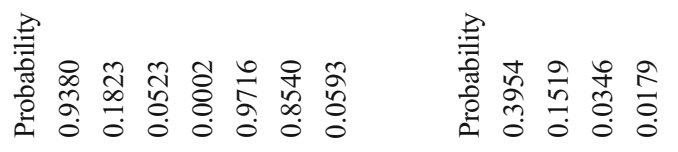

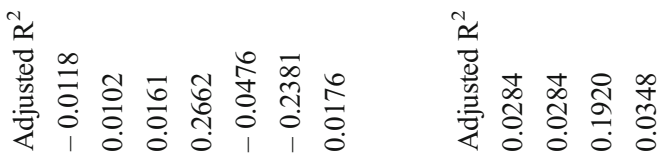

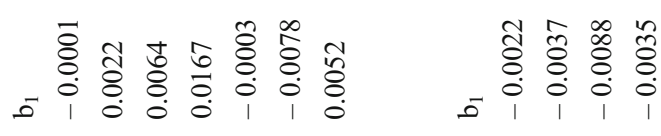

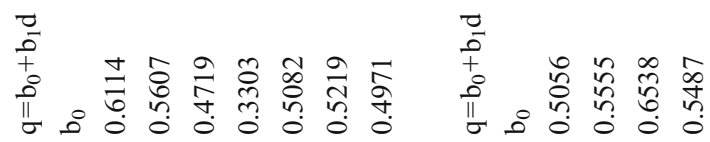

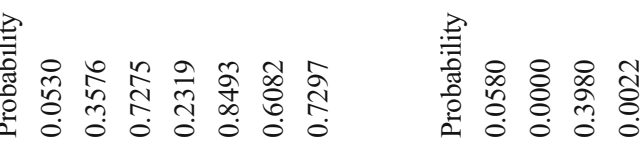

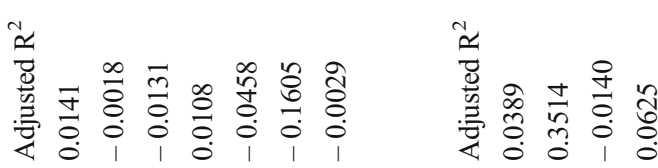

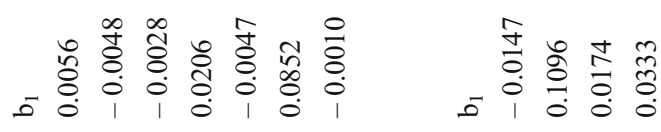

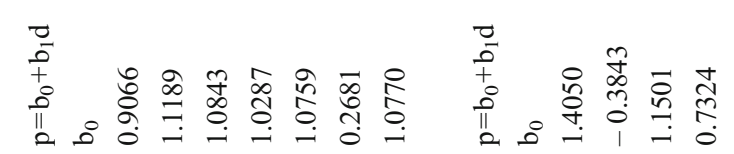

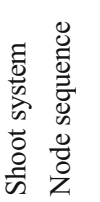

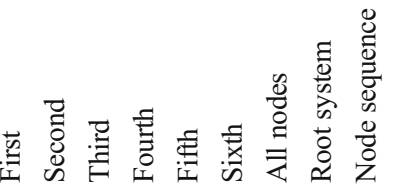

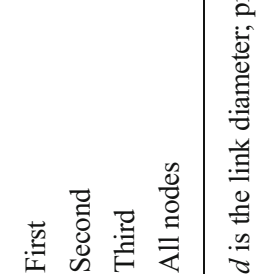


that their branching patterns could not be considered to be herringbone or to have a random growth, thereby contradicting the results of visual analysis. Nonetheless, the TI values were closer to 0.53 than to 1 , suggesting a tendency to grow randomly. On the other hand, the TT values, although not statistically different from 1 and 0 , were considerably closer to 1 for the shoot system (a tendency to assume the herringbone branching pattern) and 0 for the root system (a tendency to assume the dichotomous branching pattern).

The TI might indicate a non-herringbone branching pattern since $A$. johnsonii has multiple laterals per stem or taproot node. However, the herringbone mathematical tree based on which TI is calculated, as described by Fitter (1987), Fitter and Stickland (1991), Spek and van Noordwijk (1994), Larkin (1995), van Noordwijk and Purnomosidhi (1995), Richardson and zu Dohna (2003), and Riccardo (2007), has only one lateral per node, and thus, $a$ is equal to $\mu$, as revealed by Fitter (1991), and TI is equal to 1 (Martínez-Sánchez et al. 2003). However, the maximum number of laterals per node of $A$. johnsonii was 4 for the shoot system and 11 for the root system, making $\mu$ considerably larger than $a$, and thus, TI was lesser than 1 and closer to 0.53 . This
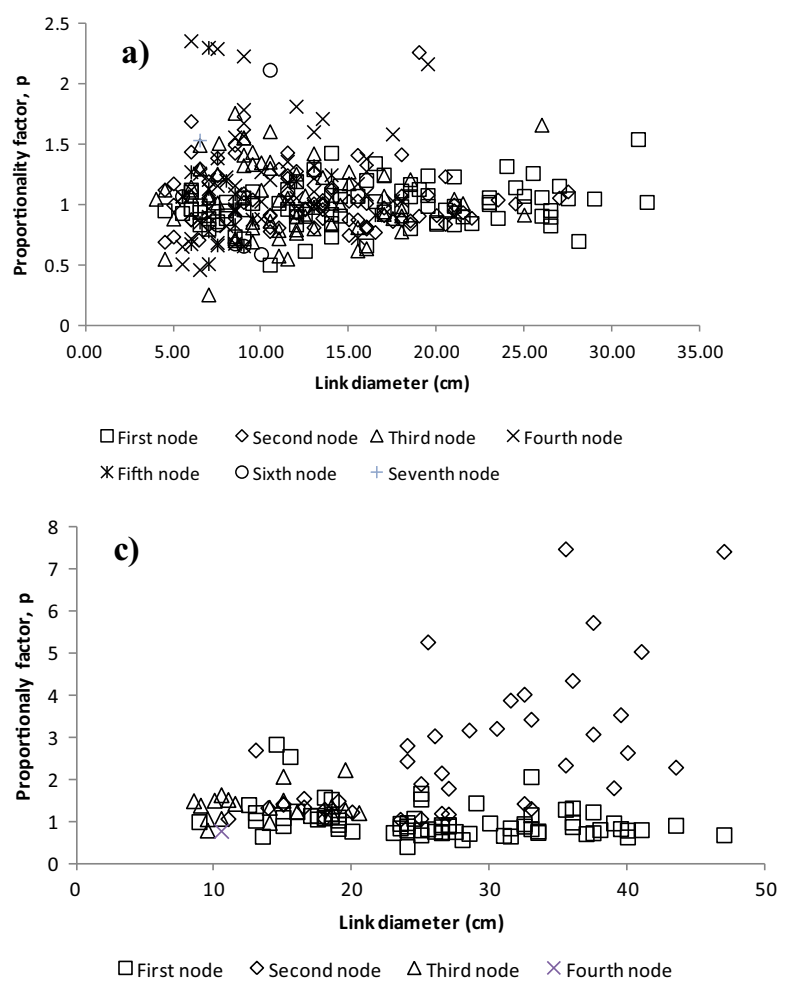

was confirmed by our results, where the average $\mu$ of the root system was 3 times the average $a$.

The same holds true for TT values, at least for the root system, since $\mathrm{P}_{(\max )}$ and $\mathrm{P}_{(\min )}$ are functions of $\mu$, making the denominator of Equation 1 larger than the numerator and causing TT to be much lesser than 1 and closer to 0 . The TT value for the shoot system was closer to 1 because the average $a$ was closer to average $\mu$, which in turn was due to the smaller number of laterals per node associated with the larger number of links, unlike in the root system.

This suggests that the TI and TT defined by Fitter et al. (1991) and Trencia (1995), respectively, might lead to biased conclusions with regards to the branching pattern when the main axis has multiple laterals per node, i.e., in these cases, a herringbone branching pattern might be regarded as a dichotomous one or as having random branching according to the topological indexes (TI and $\mathrm{TT}$ ), even if the branching pattern is clearly herringbone as is the case of the root system of A. johnsonii.

This situation can be overcome by using the modified TI (TIM) that addresses the situation of multiple laterals per node while conserving the value of TI for the cases of one lateral per node. TIM is computed as the slope of
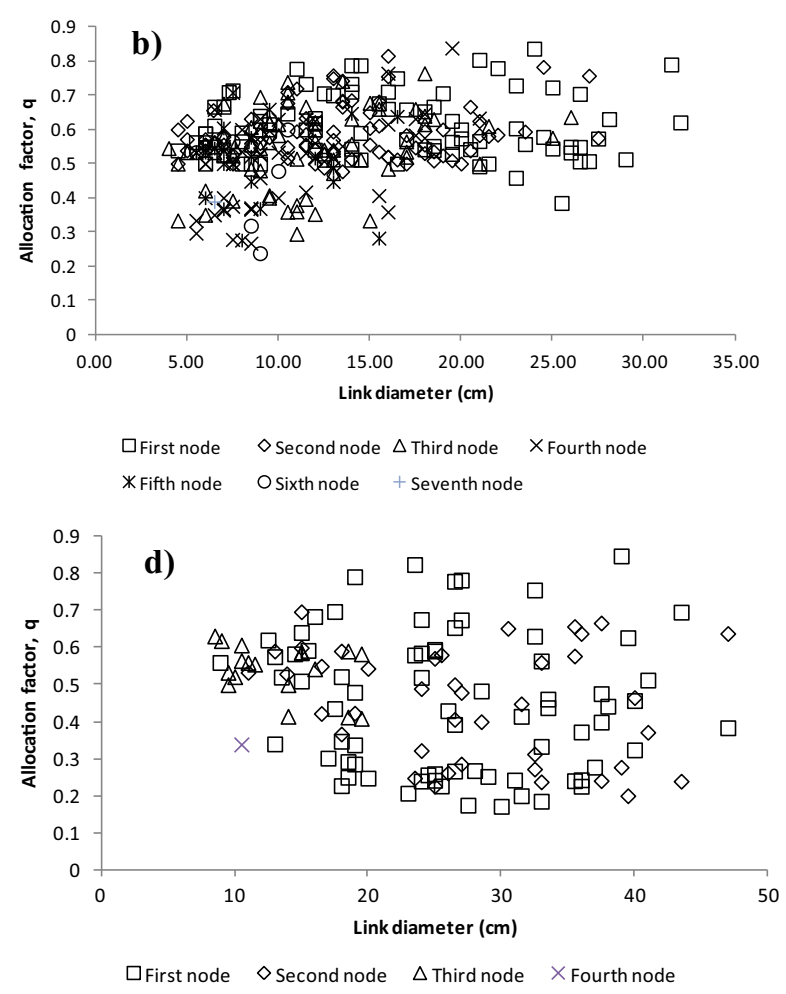

Fig. 3 Regression of branching parameters $(p$ and $q)$ against link diameter for (a, b) shoot system and (c, d) root system 
the regression between $\log _{10}(a)$ and $\log _{10}(N+1)$, where $N$ is the number of nodes in the root or shoot system. In the cases of single observation, TIM is computed as the ratio between $\log _{10}(a)$ and $\log _{10}(N+1)$.

The index TI is computed based on $\mu$ and $a$; and the modified one (TIM) is computed based on $N+1$ and $a$. Therefore, whenever a mathematical tree has only one lateral per node, the equation for TIM yields the same value as that obtained using the equations for TI described by Fitter et al. (1991), since, in this case, $\mathrm{N+}$ $1=\mu$, regardless of exhibiting a herringbone or dichotomous branching, no distinguished main axis, higherorder branching, or lateral axes with more than one link. However, the TIM value is different from the TI value when there are multiple laterals per node $(N+1 \neq \mu)$, but, nonetheless, it is consistent with the visual analyses results, and thus more realistic.

Multiple branching per node is common in the shoot system; for example, multiple laterals per stem node are found in Ceiba pentandra (L.) Gaertn, Araucaria columnaris (G. Forst.) Hook, Araucaria heterophylla (Salisb.) Franco, Pinus ponderosa Douglas, and Pinus cembra L. (visual observation).

In Fig. 4, the topological index TI described by Fitter et al. (1991) is compared with the modified one (TIM). In the herringbone branching with multiple laterals per node (Fig. 4a), although the mathematical tree has perfectly herringbone branching pattern, the TI value is much closer to 0.53 , suggesting that the tree tends to have a random growth of roots. However, the TIM indicates a perfect herringbone branching pattern consistent with the visual analysis results. For the herringbone branching with a single primary lateral per node (Fig. $4 \mathrm{~b}$ ), dichotomous branching with no laterals (Fig. 4c), when there is no distinguished main axis (Fig. 4c), and when there is
Table 7 RTO of CSA before branching $\left(\mathrm{CSA}_{\mathrm{b}}\right)$ against CSA after branching $\left(\mathrm{CSA}_{\mathrm{a}}\right)$

\begin{tabular}{llll} 
Shoot system & \multicolumn{3}{l}{} \\
Node sequence & $\mathrm{CSA}_{\mathrm{b}}=\mathrm{b}_{\mathrm{CSA}} \mathrm{a}$ & \\
& $\mathrm{b}_{1}$ & Adjusted $\mathrm{R}^{2}$ & Probability \\
First & 0.9785 & 0.9552 & 0.2750 \\
Second & 0.9791 & 0.9637 & 0.2259 \\
Third & 0.9443 & 0.9164 & 0.0781 \\
Fourth & 1.0120 & 0.9050 & 0.0830 \\
Fifth & 0.8962 & 0.9034 & 0.0688 \\
Sixth & 0.7116 & 0.6417 & 0.0909 \\
All nodes & 0.9775 & 0.9580 & 0.1002 \\
Root system & & & \\
Node sequence & $\mathrm{CSA}_{\mathrm{b}}=\mathrm{b} 1 \mathrm{CSA}_{\mathrm{a}}$ & \\
& $\mathrm{b}_{1}$ & Adjusted $\mathrm{R}^{2}$ & Probability \\
First & 0.8070 & 0.9355 & 0.0516 \\
Second & 2.1123 & 0.7322 & 0.0000 \\
Third & 1.3099 & 0.9009 & 0.0002 \\
All nodes & 0.9033 & 0.7591 & 0.3879 \\
\hline
\end{tabular}

Probability refers to the significance of the regression slope

one primary lateral per node with secondary branching (or higher-order branching) (Fig. 4d), the TIM yields the same results as TI, since $N+1=\mu$.

Further research is needed to develop a modified topological trend (TTM) that can cope with the situation of multiple laterals per node while conserving the TT values by Trencia (1995) in cases of one lateral per node.

The average value of TIM computed for $A$. johnsonii (for both the root and the shoot system) was 1, and thus consistent with the visual analysis results. The TIM was not expected to be exactly 1 for the shoot system not because the shoot system does not have a perfectly herringbone pattern since some laterals still branch, but

Table 6 Summary of the basic statistics for the diameter exponent $\Delta$

\begin{tabular}{|c|c|c|c|c|c|c|c|c|c|c|c|}
\hline \multicolumn{8}{|c|}{ Shoot system } & \multicolumn{4}{|c|}{ Root system } \\
\hline & $\Delta 1$ & $\Delta 2$ & $\Delta 3$ & $\Delta 4$ & $\Delta 5$ & $\Delta 6$ & $\Delta$ for all nodes & $\Delta 1$ & $\Delta 2$ & $\Delta 3$ & $\Delta$ for all nodes \\
\hline Minimum & 0.9700 & 0.8914 & 1.0811 & 0.6879 & 0.9031 & 0.9325 & 0.6879 & 0.7828 & 0.4858 & 0.9524 & 0.4858 \\
\hline Mean & 2.0588 & 1.9885 & 2.0319 & 1.7932 & 2.0807 & 2.2172 & 1.9968 & 1.8593 & 1.2177 & 1.5112 & 1.5407 \\
\hline Maximum & 3.8018 & 4.3501 & 4.8206 & 4.7337 & 3.3546 & 2.8178 & 4.8206 & 2.6272 & 1.9390 & 2.9877 & 2.9877 \\
\hline $\mathrm{SD}$ & 0.5360 & 0.5937 & 0.8064 & 0.7902 & 0.6564 & 0.8302 & 0.6723 & 0.4331 & 0.4169 & 0.4569 & 0.5242 \\
\hline $\mathrm{CV} \%$ & 26.0337 & 29.8564 & 39.6877 & 44.0660 & 31.5457 & 37.4408 & 33.6711 & 23.2927 & 34.2323 & 30.2350 & 34.0215 \\
\hline Probability & 0.3328 & 0.8686 & 0.7567 & 0.0935 & 0.5796 & 0.5899 & 0.9363 & 0.0596 & 0.0000 & 0.0002 & 0.0000 \\
\hline
\end{tabular}

$\Delta \mathrm{i}$ is the $\Delta$ statistic for the $i t h$ node 
because the secondary branches (those originating from the primary lateral branches) were not considered in this study and regarded as non-existing by the modified index.

A. johnsonii is a tree species found in regions with scanty rainfall and limited water resources (Mae 2005a; b; c; d; e; Dinageca 1997) and soil resources. This might be the reason why this tree species has a herringbone branching pattern of the root system (Fitter 1987; Fitter et al. 1991; Fitter and Stickland 1991; Malamy 2005; Echeverria et al. 2008).

\section{Leonardo da Vinci rule}

Van Noordwijk and Mulia (2002) suggested that a minimum of 50 but preferably 100 branching points (nodes) should be used for deriving the branching parameters. In this study, 309 and 133 branching points were used for deriving the branching parameters of the root and shoot systems, respectively.

The da Vinci rule was confirmed for each stem node and for the entire population of nodes by using four different methods: proportionality factor $p$, independence of $p$ to link diameter, diameter exponent $\Delta$, and the regression of CSA before branching against CSA after branching. The assumption of self-similarity was confirmed by the repetition of the area preserving branching (by all methods) in all stem nodes and by the independence of $p$ and $q$ to the link diameter for the entire population of nodes (Noordwijk and Purnomosidhi 1995; Richardson and zu Dohna 2003).

For the root system, the area-preserving branching was only confirmed for the first node. However, the area-preserving branching was confirmed for the entire population of nodes by using the regression between CSA before branching and that after branching. Since the area-preserving branching was not confirmed for every node and there was a significant dependence of $p$ and $q$ to link diameter for the entire population of nodes, the self-similarity was not confirmed.

The area preservation that was analysed statistically here can be explained based on eco-physiologic principles. Variations might be attributed to the effect of different heartwood proportions of the root diameter. Nikolova et al. (2009) have reported different proportions of physiologically inactive heartwood in European species, which influences the remaining capacity of a root to conduct water. Area preservation in roots and stems is better interpreted as a derivate from the physiologically
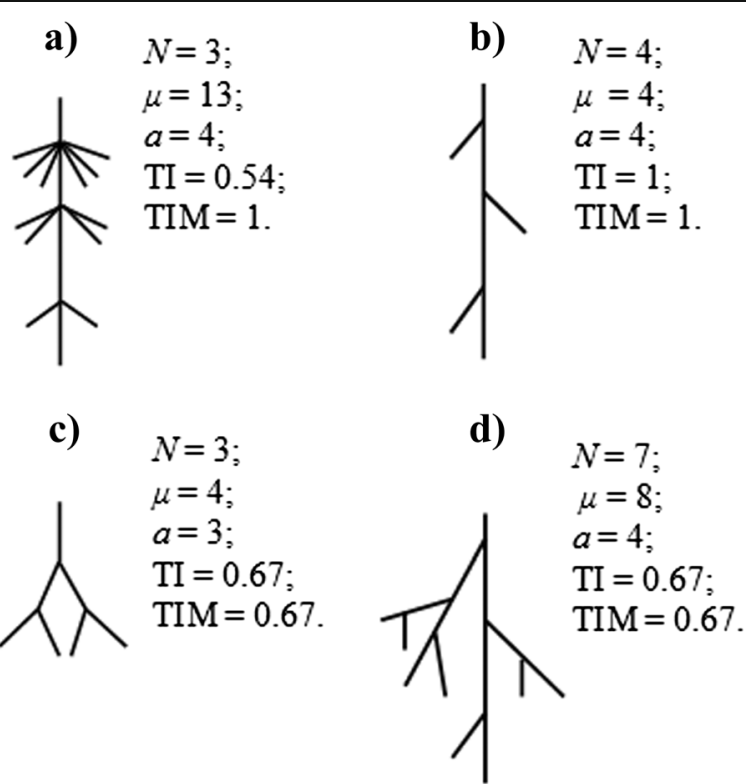

Fig. 4 Comparison of the topological index by Fitter et al. (1991) and the one modified by us for (a) herringbone branching with multiple laterals per node (b) herringbone branching with a single lateral per node, (c) dichotomous branching, and (d) dichotomous with higher-order branching. TI and TIM are computed as log (a): $\log (\mu)$ and $\log (a): \log (N+1)$ ratios, respectively

founded pipe model theory (Shinozaki et al. 1964a, b) that links the conductive sapwood area in the conductive elements of a tree to the foliage attached. Stem diameters are highly correlated with heartwood area (Seifert et al. 2006), even if Shinozaki's pipe model concept has to be extended to the real water flow in conductive elements (Nikolova et al. 2009) since doubling the size of conduits in the actively transporting sapwood increases water transport by the power of four (Schiller 1933). It has been observed for several tree species that conduits taper with increasing height in the tree, which seems to be a reason for a deviation of sapwood areas from a strict pipe-model based principle (Anfodillo et al. 2006) and might be affecting area preservation as a correlated variable as well. Here, further research would be needed to reveal the relationships between root dimension, sapwood and conduit anatomical traits to determine water conducting capacity in A. johnsonii.

The average proportionality factor $p$ for each stem node and the overall average $p$ for the entire population of stem nodes were in the range of those of the shoot system (Noordwijk and Purnomosidhi 1995). Similar results were obtained by using the average $p$ of the root system to those reported by Noordwijk and Purnomosidhi (1995), except for the second node. 
The diameter exponent $\Delta$ in this study for the root and shoot systems was in the range of those reported by Oppelt et al. (2001) and Richardson and zu Dohna (2003), although, in this case, the self-similarity was only confirmed for the shoot system. Further, the lack of dependence of $p$ and $q$ to link diameter of the shoot system and for the first taproot node was also in accordance with the finding by Noordwijk and Purnomosidhi (1995), Soethe et al. (2007), and Salas et al. (2004).

The average $p$ for the second and third taproot nodes suggested that the CSA decreased with branching since the average $p$ values were larger than 1 . However, this contradicts the conclusion obtained using average $\Delta$, since, for the second and third nodes, the average $\Delta$ values were markedly smaller than 2 , suggesting that the CSA increased with branching. These contradictions are attributed to the fact that, for 34 of the 133 observed taproot nodes, there was no solution for $\Delta$, which affected each node's average $\Delta$ and the overall average $\Delta$.

\section{Conclusion}

The newly developed topological index TIM is an unbiased estimator of the branching tendency, since this index considers both the situations of single and multiple branching per node as opposed to the traditionally used topological index TI. The branching topology of the root and shoot systems of $A$. johnsonii trees was found to be perfectly to nearly herringbone, respectively. The area preserving branching was confirmed for each stem node, thereby confirming the self-similar branching. For the root system, the area preserving branching was only confirmed for the first node; therefore, the self-similarity was not confirmed.

Acknowledgments This study was funded by the Swedish International Development Cooperation Agency (SIDA).

Conflicts of interest The author(s) declare that they have no competing interests

Open Access This article is distributed under the terms of the Creative Commons Attribution 4.0 International License (http:// creativecommons.org/licenses/by/4.0/), which permits unrestricted use, distribution, and reproduction in any medium, provided you give appropriate credit to the original author(s) and the source, provide a link to the Creative Commons license, and indicate if changes were made.

\section{References}

Anfodillo T, Carraro V, Carrer M, Fior C, Rossi S (2006) Convergent tapering of xylem conduits in different woody species. New Phytol 169(2):279-290

Berntson GM (1997) Topological scalling and plant root architecture: developmental and functional hierarchies. New Phytol 135:621-634

Cardoso GA (1963) Madeiras de Moçambique: Androstachys johnsonii. serviços de agricultura e serviços de veterinária. Maputo, Moçambique

Chiatante D, Di Iorio A, Scippa GS, Schirone B (2004) Root architectural and morphological response of Pinus Nigra Arn. and Quercus robur L. to nutrient supply and root density in the soil. Annali di Botanica 4:159-170

Coll L, Potvin C, Messier C, Delagrange S (2008) Root architecture and allocation patterns of eight tropical native species with different successional status used in open-grown mixed plantations in Panama. Trees 22:585-596. doi:10.1007/ s00468-008-0219-6

Cortina J, Green JJ, Baddeley JA, Watson CA (2008) Root morphology and water transport of Pistacia lentiscus seedlings under contrasting water supply: a test of the pipe stem theory. Environ Exp Bot 62:343-350. doi:10.1016/j.envexpbot. 2007.10.007

DINAGECA (1997) Mapa digital de uso e cobertura de terra. projecto de mapeamento de uso e cobertura de terra. CENA CARTA, Maputo

Echeverria M, Scambato AA, Sannazarro AI, Maiale S, Ruiz OA, Menéndez AB (2008) Phenotypic plasticity with respect to salt stress response by Lotus glaber: the role of its AM fungal and rhizobial symbionts. Mycorrhiza 18(6-7):317-329. doi: $10.1007 / \mathrm{s} 00572-008-0184-3$

FAO (2003) FAO map of world soil resources. FAO, Rome

Fitter AH (1987) An architectural approach to the comparative ecology of plant root system. New Phytol 106:61-77

Fitter AH (1991) Characteristics and function of root systems. In: Waissel Y, Eshel A, Kafkafi U (eds) Plant roots: the hidden half. Marcel Dekker, New York, pp 3-25

Fitter AH, Stickland TR (1991) Architectural analysis of plant root system 2. influence of nutrient supply on architecture in contrasting plant species. New Phytol 118:383-389

Fitter AH, Stickland TR, Harvey GWW (1991) Architectural analysis of plant root system 3. architectural correlates of exploitation efficiency. New Phytol 118:375-382

Glimskar A (2000) Estimates of root system topology of five plant species grown at steady-state nutrition. Plant Soil 227:249-256

Kalliokoski T (2011) Root system traits of Norway spruce, Scots pine, and silver birch in mixed boreal forests: an analysis of root architecture, morphology, and anatomy. Dissertation, University of Helsinki

Kalliokoski T, Nygren P, Siev nen R (2008) Coarse root architecture of three boreal tree species growing in mixed stands. Silva Fennica 42(2):189-210

Larkin RP, English JT, Mihail JD (1995) Effects of infection by Pythium spp. on root system morphology of alfalfa seedlings. Phyto-Pathol 85:430-435

Lynch J (1995) Root achitecture and plant produtivity. Plant Physiol 109:7-13 
Lynch JP, Ho MD (2005) Rhizoeconomics: carbon costs of phosphorus acquisition. Plant Soil 269:45-56

Mae (2005a) Perfil do distrito de Chibuto, província de Gaza. Mae, Maputo, Moçambique

Mae (2005b) Perfil do distrito de Funhalouro, província de Inhambane. Mae, Maputo, Moçambique

Mae (2005c) Perfil do distrito de Mabote, província de Inhambane. Mae, Maputo, Moçambique

Mae (2005d) Perfil do distrito de Mandhlakaze, província de Gaza. Mae, Maputo, Moçambique

Mae (2005e) Perfil do distrito de Panda, província de Inhambane. Mae, Maputo, Moçambique

Malamy JE (2005) Intrinsic and environmental response pathways that regulate root system architecture. Plant Cell Environ 28:67-77

Mantilla J, Timane R (2005) Orientação para maneio de mecrusse. SymfoDesign, Lda. Maputo, Mozambique

Martínez-Sánchez JJ, Ferrandis B, Trabaud L, Galindo R, Franco JA, Herranz JM (2003) Comparative root system structure of post-fire Pinus halepensis Mill. and Cistus monspeliensis L. saplings. Plant Ecol 168:309-320

Nicotra AB, Babicka N, Westoby M (2002) Seedling root anatomy and morphology: an examination of ecological differentiation with rainfall using phylogenetically independent contrasts. Oecologia 130:136-145

Nikolova P, Blaschke H, Matyssek R, Pretzsch H, Seifert T (2009) Combined application of computer tomography and light microscopy for analysis of conductive xylem area of beech and spruce coarse roots. Eur J For Res 128(2):145-153

Oppelt AL, Kurth W, Dzierzon H, Jentschke G, Godbold DL (2000) Structure and fractal dimensions of root systems of four co-occuring fruit tree species from Botswana. Ann For Sci 57:463-475

Oppelt AL, Kurth W, Godbold DL (2001) Topology, scaling and Leonardo's rule in root system from African tree species. Tree Physiol 21:117-128

Riccardo LB (2007) Root topology and allocation patterns of Atriplex patula seedlings supplied with different nutrient concentrations. Italian J Agrometeorol 2:35-39

Richardson AD, zu Dohna H (2003) Predicting root biomass from branching patterns of Douglas-fir root systems. OIKOS 100: 96-104

Salas E, Ozier-Lafontaine H, Nygren P (2004) A fractal root model for estimating the root biomass and architecture in two tropical legume tree species. Ann For Sci 61:337-345. doi:10. 1051/forest:2004027

Schiller L (1933) Ed. Drei Klassiker der Strömungslehre: Hagen, Poiseuille, Hagenbach. Akademische Verlagsgesellschaft, Leipzig
Seifert T, Schuck J, Block J, Pretzsch H (2006) Simulation von Biomasse- und Nährstoffgehalt von Waldbäumen mit dem Waldwachstumssimulator SILVA. Tagungsband der Jahrestagung der Sektion Ertragskunde im Deutschen Verband Forstlicher Forschungsanstalten, 208-223

Shinozaki K, Yoda K, Hozumi K, Kira T (1964a) A quantitative analysis of plant form-the pipe model theory. I. basic analyses. Jpn Ecol 14:97-105

Shinozaki K, Yoda K, Hozumi K, Kira T (1964b) A quantitative analysis of plant form- the pipe model theory: II. further evidence of the theory and its application in forest ecology. Jpn Ecol 14:133-139

Soethe N, Lehmann J, Engels C (2007) Root tapering between branching points should be included in fractal root system analysis. Ecol Model 207:363-366. doi:10.1016/ j.ecolmodel.2007.05.007

Spanos I, Ganatsas P, Raftoyannis Y (2008) The root system architecture of young Greek fir (Abies cephalonica Loudon) trees. Plant Biosyst 142(2):414-419

Spek LY, van Noordwijk M (1994) Proximal root diameter as predictor of total root size for fractal branching. II. numerical model. Plant Soil 164:119-127

Trencia J (1995) Identification de descripteurs morphomètriques sensibles aux conditions gènèrales croissance des semis de chêne rouge (Quercus rubra) en milieu naturale. Can J Forest Res 25:157-165

Trubat R, Cortina J, Vilagrosa A (2012) Root architecture and hydraulic conductance in nutrient deprived Pistacia lentiscus L. seedlings. Oecologia 170(4):899-908. doi:10.1007/ s00442-012-2380-2

Tworkoski T, Scorza R (2001) Root and shoot characteristics of peach trees with different growth habitats. J Am Soc Hort Sci 126(6):785-790

Valladares F (1999) Architecture, ecology and evolution of plant crowns. In: Valladares F, Pugnaire FI (eds) Handbook of functional plant ecology. Marcel Dekker, Inc, New York, pp 121-194

Valladares F, Pearcy RW (2000) The role of crown architecture for light harvesting and carbon gain in extreme light environments assessed with a structurally realistic 3-D model. Anales Jard Bot Madrid 58(1):3-16

Van Noordwijk M, Mulia R (2002) Functional branch analysis as tool for fractal scaling above- and belowground trees for their additive and non-additive properties. Ecol Model 149:41-51

Van Noordwijk M, Purnomosidhi P (1995) Root architecture in relation to tree-soil-crop interactions and shoot pruning in agroforestry. Agrofor Syst 30:161-173 